Athens Journal of Health - Volume 3, Issue 3-Pages 217-228

\title{
Is There a Relationship Between Night Shift and Errors? What Nurse Leaders Need to Know
}

\author{
By Vickie Hughes ${ }^{*}$
}

\begin{abstract}
The aim of this systematic review was to examine the evidence regarding nurse night shift errors. Night shift work has historically been associated with circadian rhythm changes, health risks, and even emotional effects. An electronic literature search for "night shift nurse errors" was conducted using Pubmed, CINAHL, Health Source: Nursing/Academic Edition, and Cochrane Collection Plus databases. Inclusion criteria was English language, full text available, and published dates between May 1, 2005 and May 1, 2015. Ten studies were selected for analysis based on the inclusion criteria. The quality of the studies and the level of evidence were categorized based on Johns Hopkins Strength of Evidence Hierarchy. The error rate on night shift was consistently higher than the day shift rates. Nursing factors related to the occurrence of both near misses and adverse events included fewer years of experience, increased frequency of night shifts, internal ward assignments and experiencing time pressure.
\end{abstract}

Keywords: Errors, Night shift, Nurse.

\section{Introduction}

The literature contains multiple descriptive studies that indicate rotating and chronic night shift work is associated with many health risks for nurses. The severity of health risks reported tend to increase with the number of years of rotating night shiftwork. Some of the health risks findings associated with night shift work that have been documented include increased risk of obesity for American, Korean and Canadian nurses (Kroenke et al. 2007, Zhao et al. 2012, Kim et al. 2013, Smith et al. 2013), Type II diabetes (Kroenke et al. 2007, Pan et al. 2011), lung cancer (Schernhammer et al. 2013), menstrual disturbances (Lawson et al. 2015), stroke (Brown et al. 2009), fractures (Feskanich et al. 2008), hypertension or lack of blood pressure recovery (Gangwisch et al. 2013, Lo et al. 2008), thyroid disease (Burdelak et al. 2012), breast cancer (Schernhammer et al. 2006, Kolstad 2008, Megdal et al. 2005, Hansen and Stevens 2011, Ijax et al. 2013), irritable bowel syndrome (Nojkov et al. 2010), and cardiovascular disease (Wang et al. 2011). Rotating night shift too quickly has also been associated with an increase in anxiety and depression (Chang et al. 2014a, Chang et al. 2014b).

Admi et al. (2008) discovered that although night shift nurses complained significantly more about difficulties falling asleep, morning sleepiness, headaches upon awakenings and excessive daytime sleepiness, there was not any significant association between the "adaptive nurses" and the "non-adaptive" nurses in regard to reported clinical error and adverse patient incidents. In other words, the nurses who developed symptoms of poor coping with rotating night shift work did not commit any more errors than the nurses who adapted well to night shift work.

\footnotetext{
* Associate Professor, Appalachian State University, USA.
} 


\section{Purpose and Objectives}

The purpose of this systematic review is to analyze the published evidence to determine if there is an association between night shift rotations and nurse error rates. In addition, specific factors identified within nurse night shift work that might negatively impact patient outcomes will be examined and discussed.

\section{Methodology}

A systematic review was used to examine the relationship between nurse night shift and nurse errors. An electronic literature search for "nurse night shift errors" was conducted using the Pubmed, CINAHL, Health Source: Nursing/ Academic Edition, and Cochrane Collection Plus databases. Inclusion criteria included English language, human studies, full text available articles, and published dates between May 1, 2005 and May 1, 2015. Based on the search criteria a total of 52 articles were identified. Abstracts for the identified articles were reviewed for relevance and duplicate citations were removed. Reference lists were also reviewed for relevancy, resulting in a total of 10 articles involving populations of nurses from Japan, China, Turkey, Saudi Arabia and the United States being included in the systematic review (Table 1).

\section{Analysis of Quality}

The 10 studies were reviewed and categorized according to level of evidence and the quality of rating of scientific evidence based on Johns Hopkins Strength of Evidence Hierarchy. Nine of the studies were considered as Level 3 studies and one study was considered as a Level 2 study based on the strength of the evidence. Three of the studies had insufficient sample sizes, so were rated as low quality. Five of the studies were assessed as good quality and two of the studies were assessed as high quality. Because of the small sample size for the systematic review, no study was eliminated based on quality factors but quality factors were included as part of the summary of findings.

\section{Results}

Miller et al. (2010) compared reported medication error rates in a descriptive retrospective study over a 1-year period between daytime and nighttime shifts in a children's hospital. The investigators also examined the weekday versus the weekend error rates and characteristics of the type of errors that occurred. The results indicated that the error rate for nighttime nursing shifts was significantly higher than the error rate during daytime nursing shifts $(\mathrm{p}=0.005)$. 
Table 1. Completed Checklist for Quality Items

\begin{tabular}{|c|c|c|c|c|c|c|c|c|c|c|}
\hline Authors & Sample size adequate & $\begin{array}{l}\text { Participants } \\
\text { randomized }\end{array}$ & Intervention & \begin{tabular}{|c|} 
Control \\
group
\end{tabular} & $\begin{array}{l}\text { Groups } \\
\text { equally } \\
\text { treated }\end{array}$ & $\begin{array}{l}\text { Adequate } \\
\text { data } \\
\text { collection }\end{array}$ & $\begin{array}{c}\text { Results } \\
\text { clearly } \\
\text { presented }\end{array}$ & $\begin{array}{c}\text { Interpretation } \\
\text { and analysis provided }\end{array}$ & $\begin{array}{c}\text { Conclusion } \\
\text { based on clear } \\
\text { results }\end{array}$ & $\begin{array}{c}\text { Study } \\
\text { limitation } \\
\text { discussed }\end{array}$ \\
\hline $\begin{array}{l}\text { Johnson et } \\
\text { al. }\end{array}$ & $\begin{array}{l}\text { Yes ( } 280 \text { needed) initially, } \\
\text { but then no; dropped below } \\
\text { needed sample size }(255)\end{array}$ & N/A & N/A & N/A & N/A & Yes & Yes & $\begin{array}{c}\text { Yes. Descriptive Stats, General Linear } \\
\text { model, logistic regression }\end{array}$ & $\begin{array}{c}\text { Because of small } \\
\text { sample size, limited } \\
\text { confidence in results }\end{array}$ & Yes \\
\hline Miller et al. & $\begin{array}{c}\text { Maybe; } 148 \text { in sample; no } \\
\text { power analysis reported }\end{array}$ & N/A & N/A & N/A & N/A & Yes & Yes & $\begin{array}{c}\text { Yes, Cohen's Stat for interrater } \\
\text { agreement \& Pearson's Chi Square }\end{array}$ & $\begin{array}{l}\text { Yes; noted very small } \\
\text { sample size in one } \\
\text { category }\end{array}$ & Yes \\
\hline $\begin{array}{l}\text { Alemdar et } \\
\text { al. }\end{array}$ & $\begin{array}{c}\text { No; } 78 \text { nurses; no info on } \\
\text { power }\end{array}$ & N/A & N/A & N/A & N/A & & $\begin{array}{c}\text { Yes; } \\
\text { descriptive } \\
\text { stats }\end{array}$ & Yes, very basic percentage data & $\begin{array}{l}\text { Limited strength of } \\
\text { conclusion due to } \\
\text { basic analysis of data } \\
\text { and no power }\end{array}$ & No \\
\hline Niu et al. & $\begin{array}{c}\text { Yes; } 62 \text { nurses; G-power } \\
\text { indicated need } 30 \text { subjects } \\
\text { per group }\end{array}$ & Yes & Yes & Yes & Yes & Yes & Yes & $\begin{array}{l}\text { Yes; descriptive, chi-square, t-test, } \\
\text { Mann-Whitney test, and generalized } \\
\text { estimate equations. }\end{array}$ & Yes & Yes \\
\hline $\begin{array}{l}\text { Ramadan } \\
\text { and Al- } \\
\text { Saleh }\end{array}$ & $\begin{array}{l}\text { Maybe; } 138 \text { nurses; author } \\
\text { stated number sufficient, } \\
\text { but no power reported }\end{array}$ & N/A & N/A & N/A & N/A & Yes & Yes & $\begin{array}{l}\text { Yes; descriptive, correlational } \\
\text { analysis, test conformity, adjusted for } \\
\text { covariates }\end{array}$ & Yes & Yes \\
\hline Chang & $\begin{array}{l}\text { No; only } 62 \text { nurses parti- } \\
\text { cipated in the study; no } \\
\text { power analysis was reported }\end{array}$ & Yes & Yes & No & Yes & Yes & Yes & $\begin{array}{c}\text { Yes; one-way analysis of variance, } \\
\text { Scheffe's post-hoc test, and Chi- } \\
\text { squared test. }\end{array}$ & $\begin{array}{c}\text { Limited strength of } \\
\text { conclusion due no } \\
\text { power }\end{array}$ & Yes \\
\hline $\begin{array}{l}\text { Arimura et } \\
\text { al. }\end{array}$ & $\begin{array}{l}\text { Maybe; } 454 \text { nurses with } \\
77.9 \% \text { response rate, but no } \\
\text { power reported }\end{array}$ & N/A & N/A & N/A & N/A & Yes & Yes & $\begin{array}{l}\text { Yes; univariate analyses, multiple } \\
\text { regression, and t-tests analyses }\end{array}$ & Yes & Yes \\
\hline Tanaka & Yes; 1,407 nurses & N/A & N/A & N/A & N/A & Yes & Yes & $\begin{array}{l}\text { Yes; used Poisson generalizing } \\
\text { estimating equation model to adjust } \\
\text { for potential confounding factors; data } \\
\text { analysis with Bivariate ana-lysis, } \\
\text { Fisher's exact test and t-tests. }\end{array}$ & Yes & Yes \\
\hline Tanaka & Yes; 1,737 nurses & N/A & N/A & N/A & N/A & Yes & Yes & $\begin{array}{l}\text { Yes; multivariable analysis, Fisher's } \\
\text { exact test, and logistic regression } \\
\text { analysis. }\end{array}$ & Yes & Yes \\
\hline Arakawa & $\begin{array}{c}\text { Yes; sample size of 6,445 } \\
\text { nurses }\end{array}$ & N/A & N/A & N/A & N/A & Yes & Yes & $\begin{array}{c}\text { Yes; descriptive table, bivariate } \\
\text { analysis, and logistic regression. } \\
\text { analysis }\end{array}$ & Yes & Yes \\
\hline
\end{tabular}


There was no significant difference between the reported weekend error rate and the weekday error rate except for weekend error related to first shift on weekday. The weekend rate was greater on the weekend compared to the first shift error rate during the week $(\mathrm{p}=0.004)$. Errors in medication administration occurred most frequently.

Chang et al. (2011) conducted a correlational study of 62 nurses from a psychiatric ward in Taiwan. The study compared cognitive performance at 3-4 $\mathrm{am}$, considered to be the time frame of maximum fatigue, on the last night shift of the rotation between nurses working two, three and four consecutive night shifts. The investigator used several standardized measurements to assess the anxiety, sleepiness, executive functioning, attention processing, and cognitive, perceptual and motor ability. Information on validity and reliability was presented for some but not all of the instruments. Significant differences were only found on the Digit Symbol Substitution Test $(\mathrm{p}=0.035)$, the Symbol Searching Test $(\mathrm{p}=0.045)$, and the information processing scale in Taiwan University Attention Test $(\mathrm{p}=0.030)$ between the group that worked two consecutive night shifts and the group who worked four consecutive night shifts. Conclusions indicated that the subjects who worked two consecutive night shifts had poorer perceptual and motor ability than those who worked four consecutive night shifts. The major duties that were identified as having greatest risk for impact were checking medical orders and prescriptions which required similar skills as completing the Symbol Searching Test and the Digit Symbol Substitution Test. With the reduced information processing index, the perceptual speed would be diminished. The investigators hypothesized that a fast shift rotation may increase the risk of medical errors based on the perceptual and motor changes identified with these measurements.

A second study of attention levels in nurses who worked in a Taiwan hospital was found during the systematic review. However, Niu et al. (2012) compared the attention levels and percentage of errors of 62 nurses working different shifts. All of the nurses in the study were randomly assigned to the fixed shift group or the rotating shift group. The investigators considered the shift schedule to be a control variable in the study. Information on psychometric properties and reliability were reported for measurements utilized with the subjects. The night shift workers had significantly higher error rates and poorer overall performance speeds (as measured in the $\mathrm{d} 2$ test developed by Brickenkampe and Zillmer) compared to day and evening shift workers. The reported error rate on the night shift was 0.44 times more than the day shift $(p<0.001)$ and 0.62 times more than the evening shift $(p=0.001)$. The performance and accuracy scores of the shift workers was significantly less than the control group $(\mathrm{p}<0.01)$.

Four studies were found that investigated factors associated with medical errors by Japanese nurses. Alemdar et al. (2013) conducted a descriptive study utilizing surveys from 454 nurses working in two medium scale Japanese hospitals to investigate the relationship between shift work, mental health and medical errors. The surveys were conducted using identical, anonymous self-administered questionnaires that contained demographic data, shift work information, workload, 
involvement in traffic accident during past 12 months, and medical errors. In addition the Epworth Sleepiness Scale, the Pittsburg Sleep quality index, and the General Health Questionnaire were administered to assess for sleepiness, mental health status and sleep quality. Multivariate analysis indicated that shift workers had significantly more errors $(\mathrm{p}=0.001)$ compared to day shift only workers. In addition, lower scores on the General Health Questionnaire were also associated with more medical errors $(\mathrm{p}<0.001)$. The author concluded that shift work and poor mental health were significant factors contributing to medical errors.

In a second study, Arakawa et al. (2011) analyzed surveys completed by 6,445 female nurses who were engaged in shift work within one of 93 Japanese hospitals. The purpose of the study was to investigate a relationship between medical errors that occurred within the last 6 months and lifestyle, health, and work environment factors. A total of $79.3 \%(5,112)$ of nurses reported that they had made medical errors or experienced medical incidents during the last six months. Medical incidents were defined as cases in which treatment was not affected because either the error was detected in a timely manner or corrective measures were taken. Errors were defined as non-negligent events. Environmental factors that correlated with increased medical errors included working on outpatient department versus wards $(p<0.0001)$, higher heaviness of workload during the night shift $(\mathrm{p}<0.0001)$, number of night shifts per month $(\mathrm{p}<0.006)$, decreased frequency of no overtime hours of work during the night shift $(\mathrm{p}<0.0001)$, and increased stress due to night shifts $(\mathrm{p}<0.0001)$. In addition, the investigators noted that an increase in break time during night shifts was also predictive of medical incidents/errors. Health factors that were found to be associated with accomplishing medical errors included being under treatment $(\mathrm{p}=0.001)$, absence from work due to sickness during the past 6 months $(\mathrm{p}<0.0001)$, bodily pain $(\mathrm{p}=0.011)$, and emotional problems $(\mathrm{p}=0.007)$.

Two additional studies examined nurse medical errors and near miss events in relation to night shifts at Japanese teaching hospitals. Tanaka et al. (2010a) surveyed 1,860 registered nurses working in 5 teaching hospitals in Japan via selfreport questionnaires. The questionnaires gathered demographic data, lifestyle patterns, and work environment information. A second questionnaire inquired about frequency of self-perceived near misses and adverse events experienced in the last six months. In addition, the Nursing Stress and Hospital Anxiety and Depression scales were administered to gather information regarding nursingspecific job stress, depression and anxiety. A total of 1,407 nurses worked a rotation schedule to include night shifts. Data was analyzed using multivariate analysis. Factors found to be significantly related to the occurrence of both near misses and adverse events included fewer years of experience $(p<0.001)$, increased frequency of night shifts $(\mathrm{p}<0.001)$, internal ward assignments $(\mathrm{p}<0.02)$, lack of communication $(\mathrm{p}<0.001)$, nursing stressors $(\mathrm{p}<0.001)$ and experiencing time pressure $(p<0.02)$. In addition, increased depression scores $(p<0.08)$ were also associated with an increased frequency of near miss events.

Tanaka et al. (2010b) compared the medical error risk among nurses working two shift (16 hour shifts) and three shift ( 8 hour shifts) systems. All shift work included night work. The investigators collected self-reported questionnaires from 
1,407 registered nurses working at teaching hospitals in Japan. Bivariate analysis was performed to determine the variables for multivariate analysis. Fishers' exact test was used to analyze categorical variables and the t-test to analyze continuous variables. A log Poisson GEE was used because the distribution frequencies of adverse events was anticipated to be a Poisson distribution. After adjusting for years of experience and number of night shifts per month, the results indicated that nurses working in the three-shift system had a significantly higher perception of perceived adverse events than the nurses working in the two-shift system $(\mathrm{p}<0.001)$.

Arimura et al. (2010) conducted a descriptive correlational study by surveying 454 nurses who worked at one of two hospitals located in Shiga Prefecture, Japan. The identical, anonymous self-administered questionnaires inquired on involvement in a "medical error" within the past month. The questionnaire also involved questions regarding demographic variables, work load, health habits, frequency of night shifts, and life style factors. In addition the Epworth Sleepiness Scale and the Pittsburgh Sleep Quality Index were also administered to assess sleepiness, mental health status and sleep quality. Data was examined using univariate analyses, multiple logistic regression analysis, and t-tests. Univariate analyses revealed significant differences between the "with error" and the "without error" groups with respect to night shift work and poor mental health $(p<0.05)$. The "with error" group of nurses tended to have "poor mental health" and worked night shift rather than day shifts.

In addition, Ramadan and Al-Saleh (2014) conducted a study of 138 registered nurses working night shift in an intensive care department in Saudi Arabia to examine a relationship between sleep deprivation and the occurrence of errors via self-reported questionnaires. The questionnaires included items on the Pittsburgh Sleep Quality Index, demographic characteristics, and reported medical errors. The data was analyzed using correlation and stepwise logistic multiple regression. The investigators discovered that "sleep-deprived nurses had higher number of medical errors per participant when compared to non-sleep deprived nurses at 8-,10-, 12-shift lengths, $\mathrm{p}<0.001, \mathrm{p}<0.014$, and $\mathrm{p}<0.001$, respectively" ( $\mathrm{p}$. 100 ). In addition, the authors found that the greater the number of work hours per week, the higher the number of medical errors.

Similarly, Johnson et al. (2014) investigated the relationship between sleep deprivation and errors among staff who worked the night shift in a cross sectional, correlational study of 219 nurses. A general linear model was used to test for association between sleep deprivation, number of hours slept and patient care errors. The investigators controlled for selected covariates. Model fit and conformity to model assumptions were tested. Number of hours slept was determined from a sleep diary. The patient care errors were self-reported by the nurses. Demographic data and shift work data were gathered from a questionnaire. After for controlling for covariates, the results indicated that sleep deprived nurses reported more patient care errors than non-sleep deprived nurses $(\mathrm{p}=0.005)$. The sample size of this study was smaller than anticipated due to missing data resulting in a reduced power of the tests. No psychometric evaluation measures were performed, so no information on validity and reliability. 
Alemdar et al. (2013) examined the medical error types and causes by Turkish nurses in a descriptive study of 78 nurses from a randomly selected hospital in Giresun city center. The common types of medical errors discovered were hospital infection rate, diagnostic errors, needle or cutting tool injuries and problems related due drug usage. The self-reported causes of the medical errors in the study were $38.5 \%$ of nurses as tiredness, $36.4 \%$ of nurses as increased workload and $34.6 \%$ of nurses as long working hours (Table 2).

\section{Synthesis of Findings}

The error rate for nurses working night shift is higher than the rate for nurses working the day shift (Miller et al. 2010, Niu et al. 2012, Arimura et al. 2010, Tanaka et al. 2010a, Arakawa et al. 2011). Fatigue and sleep deprivation contributed to more patient errors (Johnson et al. 2014, Alemdar et al. 2013, Ramadan and Al-Saleh 2014, Arimura et al. 2010. In addition, heaviness of workload (Arakawa et al. 2011, Alemdar et al. 2013), poor mental health to include depression (Arimura et al. 2010, Tanaka et al. 2010a, Arakawa et al. 2011) and extended working hours (Alemdar et al. 2013, Arakawa et al. 2011) were found to be associated with an increased error rate for night shift nurses. Nurses who work night shift were found to demonstrate poorer speed and accuracy than staff who worked the day shift (Niu et al. 2012). Furthermore Chang et al. (2011) found that greater perceptual and motor ability impairment was found in nurses who worked 2 consecutive night shifts compared to those who worked four consecutive night shifts. This finding may indicate that fast shift rotation may impact perceptual and motor ability more than slower shift rotations. Finally, Tanaka et al. (2010b) discovered that those workers who worked three 8-hour shifts schedules reported significantly more errors than the group of nurses who worked in the two 12-hour shift group.

\section{Discussion and Recommendations}

Many of the studies reviewed are based on self-report data collected through a survey method. All of the studies were descriptive and/or correlational. The error rate on night shift was consistently described as higher than the error rate on day shifts, even when the same nurses rotated both shifts. Tiredness or fatigue was one of the factors reported by the nurses as contributing to error rate. The ANA (2014) published a position statement on the nurse responsibility regarding fatigue. Some hospitals are beginning to implement fatigue management programs that focus on a shared responsibility between nurses and supervisors to prevent incidents related to fatigue. Some of these fatigue management programs restrict the number of hours the nurse can work during a shift or during a work week. Most programs are restricting the hours a nurse may be on call outside the normal work day. 
Table 2. Summary of Studies

\begin{tabular}{|c|c|c|c|}
\hline Authors & Sample & Method & Findings \\
\hline $\begin{array}{l}\text { Miller et al. } \\
(2010)\end{array}$ & $\begin{array}{l}\text { Centralized database of errors reported } \\
\text { from Jan } 2008 \text { - Dec } 2008 \text { at a 96-bed } \\
\text { academic, tertiary care children's } \\
\text { hospital }\end{array}$ & DS & Medication error rate for night shift nurses significantly higher than day time nurses $(\mathrm{p}=0.05)$ \\
\hline $\begin{array}{l}\text { Chang et al. } \\
(2011)\end{array}$ & 62 Psychiatric Nurses in Taiwan & DCS & $\begin{array}{l}\text { Significant differences found on the Digit Symbol Substitution Test ( } \mathrm{p}=0.035) \text {, the Symbol Searching Test } \\
(\mathrm{p}=0.045) \text {, and the information processing scale in Taiwan University Attention Test }(\mathrm{p}=0.030 \text { ) between } \\
\text { the group that worked two consecutive night shifts and the group who worked four consecutive night } \\
\text { shifts. A fast shift rotation may increase the risk of medical errors based on the perceptual and motor } \\
\text { changes identified with these measurements. }\end{array}$ \\
\hline $\begin{array}{l}\text { Niu et al. } \\
\text { (2012) }\end{array}$ & Taiwan & PRPGS & $\begin{array}{l}\text { The night shift workers had significantly higher error rates and poorer overall performance speeds } \\
(p<0.01) \text { compared to day and evening shift workers. The reported error rate on the night shift was } 0.44 \\
\text { times more than the day shift }(p<0.001) \text { and } 0.62 \text { times more than the evening shift ( } p=0.001 \text { ). }\end{array}$ \\
\hline $\begin{array}{l}\text { Arakawa et } \\
\text { al. (2011) }\end{array}$ & $\begin{array}{l}\text { 6,445 female hospital nurses engaged in } \\
\text { shift work (93 Japanese hospitals) }\end{array}$ & DCS & $\begin{array}{l}\text { Environmental factors correlated with increased errors included working on outpatient department ( } \mathrm{p}<0.0001) \text {, } \\
\text { higher heaviness of workload }(\mathrm{p}<0.0001) \text {, number of night shifts per month }(\mathrm{p}<0.006) \text {, decreased frequency of } \\
\text { no overtime hours }(\mathrm{p}<0.0001) \text {, and increased stress }(\mathrm{p}<0.0001) \text {. Health factors associated with medical errors } \\
\text { included being under treatment }(\mathrm{p}=0.001) \text {, absence due to sickness }(\mathrm{p}<0.0001) \text {, bodily pain ( } \mathrm{p}=0.011) \text {, and } \\
\text { emotional problems }(\mathrm{p}=0.007) \text {. }\end{array}$ \\
\hline $\begin{array}{l}\text { Tanaka et al. } \\
(2010)\end{array}$ & $\begin{array}{l}1,737 \text { nurses working in } 5 \text { teaching } \\
\text { hospitals in Tokyo and Kanagawa Japan }\end{array}$ & DCS & $\begin{array}{l}\text { Factors found to be significantly related to the occurrence of near misses and adverse events for nurses } \\
\text { working rotating shifts included fewer years of experience }(\mathrm{p}<0.001) \text {, increased frequency of night shifts } \\
(\mathrm{p}<0.001) \text {, internal ward assignments }(\mathrm{p}<0.02) \text {, lack of communication }(\mathrm{p}<0.001) \text {, nursing stressors } \\
(\mathrm{p}<0.001) \text {, depression }(\mathrm{p}<0.08) \text { and experiencing time pressure }(\mathrm{p}<0.02) \text {. }\end{array}$ \\
\hline $\begin{array}{l}\text { Tanaka et al. } \\
(2010)\end{array}$ & $\begin{array}{l}1,407 \text { nurses working shifts at one of } \\
\text { five teaching hospitals in Japan }\end{array}$ & DCS & $\begin{array}{l}\text { Nurses working in the three-shift system had a significantly higher perception of perceived adverse events } \\
\text { than the nurses working in the two-shift system }(\mathrm{p}<0.001) \text {. }\end{array}$ \\
\hline $\begin{array}{l}\text { Arimura et } \\
\text { al. }(2010)\end{array}$ & $\begin{array}{l}\text { 454 Japanese nurses ( } 2 \text { Shiga } \\
\text { Prefecture hospitals) }\end{array}$ & DCS & $\begin{array}{l}\text { Shift work and poor mental health significantly associated with medical errors }(\mathrm{p}<0.05) \text {. After adjustment for } \\
\text { burnout or depression, only fatigue and distress remained significantly significant associated with errors. }\end{array}$ \\
\hline $\begin{array}{l}\text { Ramadan } \\
\text { and Al-Saleh } \\
\text { (2014) }\end{array}$ & $\begin{array}{l}138 \text { Saudi Arabian registered nurses } \\
\text { working in intensive care department }\end{array}$ & DCS & $\begin{array}{l}\text { The investigators discovered that "sleep-deprived nurses had higher number of medical errors per } \\
\text { participant when compared to non-sleep deprived nurses at } 8-, 10-, 12 \text {-shift lengths, } \mathrm{p}<0.001, \mathrm{p}<0.014 \text {, and } \\
\text { p }<0.001 \text {, respectively". }\end{array}$ \\
\hline $\begin{array}{l}\text { Johnson et } \\
\text { al. }(2014)\end{array}$ & $\begin{array}{l}289 \text { nurses started study; } 255 \text { nurses } \\
\text { finished study }\end{array}$ & & Sleep deprived nurses reported more patient care errors than non-sleep deprived nurses ( $\mathrm{p}=0.005)$. \\
\hline $\begin{array}{l}\text { Alemdar et } \\
\text { al. (2013) }\end{array}$ & 78 Turkish nurses & DS & $\begin{array}{l}\text { Self-reported causes of the medical errors were tiredness (38.5\%), increased workload (36.4\%), and long } \\
\text { working hours }(34.6 \%) \text {. }\end{array}$ \\
\hline
\end{tabular}


Nurses may be provided education on the symptoms and hazards of fatigue and guidelines for when the nurse needs to tell the supervisor that they are not safe to work. In addition, the guidelines addressed sleep cycles, breaks, and uninterrupted periods of time away from work (Birmingham et al. 2013).

Another characteristics associated with tiredness is decision regret. Scott et al. (2014) conducted a descriptive study utilizing questionnaires from 546 members of the American Association of Critical-Care Nurses. Self-report questionnaires utilized to gather information on work-related data, sleep quality/quantity, daytime sleepiness, clinical-decision self-efficacy and decision regret. Decision regret was reported by $157 / 546$ nurses (29\%). The nurses who reported decision regret also reported more fatigue, more daytime sleepiness, worse sleep quality and less inter shift recovery than the nurses without decision regret. The highest correlations on the binary logistic regression model with decision regret were working 12-hour shifts $(\mathrm{p}=0.01)$ and low levels of clinical decision satisfaction $(\mathrm{p}<0.001)$.

Strategies to decrease sleep deprivation and improve attention during the night might be effective in reducing the night shift error rate. Moderate exercise for 30 minutes, taking a nap, and moderate caffeine consumption prior to night shift, have been shown to increase alertness. However, consuming simple sugars or intense exercise for long periods tend to increase sleepiness (Caruso and Hitchcock 2010). Ruggiero and Redeker (2014) conducted a systematic review of 13 experimental and quasi-experimental studies related to naps during the night shift. The overall findings indicate that planned naps during night shifts reduce nocturnal sleepiness and improve sleep-related performance deficits. Another factor that seems to really impact sleep deprivation is the shift rotation schedule. Allowing nurses to use a self-scheduling method may help them establish more of a work-life balance and actually have some positive health effects (Bambra et al. 2008). Another scheduling strategy is to ensure forward rotations for shift changes. In other words, moving from night shift to day shift versus night shift to evening shift. Studies indicate that it is easier for nurses to adjust to a forward rotation (Bambra et al. 2008). However, the literature is lacking on evidence-based research studies to support changes in current practice. Future research should focus on developing and testing the effectiveness of interventions designed to mitigate or reduce the risk of errors during night shift rotations.

\section{References}

Admi H, Tzischinsky O, Epstein R, Herer P, Lavie P (2008) Shift work in nursing: Is it really a risk factor for nurses' health and patients' safety? Nursing Economics 26(4): 250-257.

Alemdar DK, Akas YY, Kelimeler A (2013) Medical error types and causes made by nurses in Turkey, TAF Preventive Medicine Bulletin 21(3): 307-314.

ANA - American Nurses Association (2014). Position Statement: Addressing Nurse Fatigue to Promote Safety and Health: Joint Responsibilities of Registered Nurses and Employers to Reduce Risks. Retrieved from http://goo.gl/eaM9lp. 
Arakawa C, Kanoya Y, Sato C (2011) Factors contributing to medical errors and incidents among hospital nurses - nurse' health, quality of life, and workplace predict medical errors and incidents. Industrial Health 49: 381-388.

Arimura M, Imai M, Okawa M, Fujimura T, Yamada N (2010) Sleep, mental health status, and medical errors among hospital nurses in Japan. Industrial Health 48: 811-817.

Bambra CL, Whitehead MP, Sowden AJ, Akers J, Petticrew MP (2008) Shifting Schedules the health effects of reorganizing shift work. American Journal of Preventive Medicine 34(5): 427-434.

Birmingham SE, Dent RL, Ellerbe S (2013) Reducing the impact of RN fatigue on patient and nurse safety. Nurse Leader 11(6): 31-34.

Brown SB, Hankinson A, Eliassen H, Reeves KW, Qian J, Arcaro KF, Wegrzyn LR, Willet WC, Schernhammer ES (2009) Rotating night shift work and the risk of ischemic stroke. American Journal of Epidemiology 169(11): 155-162.

Burdelak W, Bukowska A, Krysicka J, Peplonska B (2012) Praca W Nocy a Stan Zdrowia Pielegniarek I Poloznych: Badanie Przekrojowe (Night Work and Health Status of Nurses and Midwives: Cross-Sectional Study. Medycyna Pracy 63(5): 517-529.

Caruso CC, Hitchcock EM (2010) Strategies for nurses to prevent sleep-related injuries and errors. Rehabilitation Nursing 35(5): 192-197.

Chang Y, Chen H, Wu Y, Hsu C, Lui C, Hsu C (2014a) Rotating night shifts too quickly may cause anxiety and decreased attentional performance, and impact prolactin levels during the subsequent day: a case control study. BioMed Central Psychiatry 14: 1-10.

Chang, M., Tseng, C. \& Chiou, Y. (2014b). The plasma concentration of copper and prevalence of depression were positively correlated in shift nurses," Biological Research for Nursing, 16 (2), pp. 175-181.

Chang YS, Wu YH, Hsu CY, Tang SH, Yang LL, Su SF (2011) Impairment of perceptual and motor abilities at the end of a night shift is greater in nurses working fast rotating shifts. Sleep Medicine 12: 866-869.

Feskanich D, Hankinson SE, Schernhammer ES (2008) Nightshift work and fracture risk: the Nurses' Health Study. Osteeoporos International 20: 537-542.

Gangwisch JE, Feskanich D, Malaspina D, Shen S, Forman JP (2013) Sleep duration and risk for hypertension in women: results from the nurses' health study. American Journal of Hypertension 26(7): 903-911.

Hansen J, Stevens RG (2011) Case-control study of shift-work and breast cancer risk in Danish nurses: Impact of shift systems. European Journal of Cancer 48(11): 1722-1729.

Ijax S, Verbeek J, Seidler A, Lindbohm M, Ojajarvi A, Orsini N, Costa G, Neuvonen K (2013) Night-shift work and breast cancer - a systematic review and meta-analysis. Scandinavian Journal of Work and Environmental Health 39(5): 431-447.

Johnson AL, Jung L, Brown KC, Weaver MT, Richards KC (2014) Sleep deprivation and error in nrses who work the night shift. The Journal of Nursing Administration 44(1): 17-22.

Kim M, Son K, Park H, Choi D, Lee H, Cho H, Cho M (2013) Association between shift work and obesity among female nurses: Korean Nurses' Survey. BioMed Central 13(1204), DOI: 10.1186/1471-2458-13-1204.

Kolstad HA (2008) Nightshift work and risk of breast cancer and other cancers - a critical review of the epidemiologic evidence. Scandinavian Journal of Work, Environment \& Health 34(1): 5-22. 
Kroenke C, Spiegelman D, Manson J, Schernhammer E, Colditz G, Kawachi I (2007) Work characteristics and incidence of type 2 diabetes in women. American Journal of Epidemiology 165(2): 175-183.

Lawson CC, Johnson CY, Chavarro JE, Hibert ENL, Whelan EA, Rocheleau CM, Grajewski B, Schernhammer ES, Rich-Edwards JW (2015) Work schedule and physically demanding work in relation to menstrual function: the Nurses' Health Study 3. Scandinavian Journal of Work, Environment \& Health 41(2): 194-203.

Lo S, Liau C, Hwang J, Wang J (2008) Dynamic blood pressure changes and recovery under different work shifts in young women. American Journal of Hypertension 21(7): 759-764.

Megdal SP, Kroenke CH, Laden F, Pukkala E, Schernhammer ES (2005) Night work and breast cancer risk: A systematic review and meta-analysis. European Journal of Cancer 41(13): 2023-2032.

Miller AD, Piro CC, Rudisill CN, Bookstaver PB, Bair JD, Bennett CL (2010) Nighttime and Weekend Medication Error Rates in an Inpatient Pediatric Population. The Annuals of Pharmacolotherapy 44: 1739-1746.

Nojkov, I.B., Rubenstein, J.H., Chey, W.D. \& Hoogerwerf, W.A. (2010). Impact of rotating shift work on the prevalence of irritable bowel syndrome in nurses," American Journal of Gastroenterology, vol. 105, no. 4, pp. 842-847.

Niu S, Chu H, Chen C, Chung M, Chang Y, Liao Y, Chou K (2012) A comparison of the effects of fixed- and rotating-shift schedules on nursing staff attention levels: A randomized trial. Biological Research for Nursing 15(4): 443-450.

Pan A, Schernhammer ES, Sun Q, Hu FB (2011) Rotating Night Shift Work and Risk of Type 2 Diabetes: Two Prospective Cohort Studies in Women. PLoS Medicine 8(12): e1001141, DOI: 10.1371/journal. pmed.1001141.

Ramadan MZ, Al-Saleh KS (2014) The association of sleep deprivation on the occurrence of errors by nurses who work the night shift. Current Health Sciences Journal 40(2): 97-103.

Ruggiero JS, Redeker NS (2014) Effects of napping on sleepiness and sleep-related performance deficits in night-shift workers: a systematic review. Biological Research for Nursing 16(3): 134-142.

Schernhammer ES, Feskanich D, Liang G, Han J (2013) Rotating night-shift work and lung cancer risk among female nurses in the United States. American Journal of Epidemiology 178(9): 1434-1441.

Schernhammer ES, Kroenke CH, Laden F, Hankinson SE (2006) Night Work and Risk of Breast Cancer. Epidemiology 17(1): 108-111.

Scott LD, Arslanian-Engoren C, Engoren MC (2014) Association of sleep and fatigue with decision regret among critical care nurses. American Journal of Critical Care 23(1): 13-22.

Smith P, Fritschi L, Reid A, Mustard C (2013) The relationsip between shift work and body mass index among Canadian nurses. Applied Nursing Research 26: 24-31.

Tanaka K, Otsubo T, Tanaka M, Kaku A, Nishinoue N, Takanao T, Kamata N, Miyaoka H (2010a) Similarity in predictors between near miss and adverse event among Japanese Nurses working at teaching hospitals. Industrial Health 48(6): 775-782.

Tanaka K, Takahashi M, Hiro H, Kakinuma M, Tanaka M, Kamata N, Miyaoka H (2010b) Differences in medical error risk among nurses working two- and three-shift systems at teaching hospitals: A six-month prospective study. Industrial Health 48(3): 357-364.

Wang X, Armstrong ME, Cairns BJ, Key TJ, Travis RC (2011) Shift work and chronic disease: the epidemiological evidence. Occupational Medicine 61(2): 22. 
Vol. 3, No. 3 Hughes: Is There a Relationship Between Night Shift and Errors ...

Zhao I, Bogossian F, Turner C (2012) The effects of shift work and interaction between shift work and overweight/obesity on low back pain in nurses: Results from a longitudinal study. Journal of Occupational and Environmental Medicine 54(7): 820-825. 